\title{
A linguagem como forma de habitar: o próximo e 0 distante
}

Paulo Roberto Masella Lopes

\section{Resumo}

Este ensaio pretende discutir a relação entre comunicação e cidade a partir das noções de proximidade e distância. Usualmente, concedese às novas tecnologias da comunicação $\mathrm{a}$ primazia pelo domínio do espaço virtual, assim como à arquitetura a construção dos espaços concretos da materialidade. Sem dúvida, os meios técnicos de comunicação, ao reorganizarem a percepção das distâncias, suscitam uma crise da matriz espacial;; contudo, cremos que não se possa excluir a produção de subjetividade como um processo de virtualização do pensamento que refaz o próprio sentido do espaço. Como resultado, temos que as formas de habitar não se reduzem à mensurabilidade do espaço concreto, mas dependem das linguagens que produzem a visibilidade do real.

Palavras-chave

Espaço. Linguagem. Habitar.
Paulo Roberto Masella Lopes | paulomasella@gmail.com Mestre em Ciências da Comunicação pela Universidade de São Paulo - USP.

\section{A linguagem: do logocentrismo à fenomenologia}

A concepção da linguagem como forma de habitar tem uma forte inspiração fenomenológica.

Merleau-Ponty (1999) diz que a palavra não se reduz a um signo dos objetos e das significações, mas habita as próprias coisas e veicula significações de modo que no falante, a palavra não traduz um pensamento já concebido, mas o realiza, assim como aquele que escuta recebe, pela palavra, o próprio pensamento. Já Heidegger define o Dasein (Ser aí) como modo de estar no mundo, não apenas no sentido de dar uma localização, mas uma morada (Behausung). Todavia este ser não se confunde com uma consciência ou substância pensante, mas como uma possibilidade, como um devir que encontra pela linguagem um modo de estar no mundo. Para Heidegger (2001), a linguagem não se reduz a um conjunto de signos determinados logicamente por meio dos quais se dá a comunicação de mensagens, nem a funções apofânticas em suas tentativas de descrição do real. Não é meramente instrumental, nem tampouco se restringe ao nomear ou representar apenas, mas, nos termos 
ontológicos a que se propõe a examinar, não é o homem que possui a linguagem, mas 0 contrário. Comunicar algo pela linguagem não é transmitir informações ou vivências entre sujeitos, mas partilhar sentido com os outros. Essa partilha de sentido com o outro requer, portanto, um suporte no Lebenswelt (mundo da vida) e outro na intersubjetividade, como movimento de fuga ao sujeito solipsista e à transcendência. No entanto, é atrelada ao logos que a cidade deve sua origem, desde que Platão procurou conciliar o discurso racional com os interesses da polis grega:

0 que implica 0 sistema da polis é primeiramente uma extraordinária preeminência da palavra sobre todos os outros instrumentos do poder. Torna-se instrumento político por excelência, a chave de toda a autoridade no Estado, o meio de comando e de domínio sobre outrem. [...] Entre a política e o logos, há assim relação estreita, vínculo recíproco. A arte política é essencialmente exercício da linguagem; e o logos, na origem, toma consciência de si mesmo, de suas regras, de sua eficácia, através de sua função política. (VERNANT, 1984, p. 34-35).

Opondo-se à narrativa mítica e à oralidade, "é a escrita que vai fornecer, no plano propriamente intelectual, o meio de uma cultura comum e permitir uma completa divulgação de conhecimentos previamente reservados ou interditos" (VERNANT, 1984, p. 36). É constituindo-se enquanto logos - enquanto discurso normativo - que a inteligibilidade do real será possível, possibilitando à escrita cumprir sua função de publicidade.
Em sua origem, a cidade é, portanto, uma forma de habitar marcada não só pela concretude de sua arquitetura, mas também pela escrita e por um modelo epistêmico que cria a dicotomia sujeito-objeto, interior-exterior, como modo próprio de pensar o mundo.

A relação interior-exterior, que é um aspecto principal do espaço concreto, sugere que os espaços possuem graus variados de extensão e cercamento. Enquanto as paisagens se diferenciam por terem extensões variáveis, mas basicamente contínuas, os assentamentos são entidades muradas entre fronteiras. Portanto, assentamento e paisagem mantêm entre si uma relação de figura-fundo. De modo geral, tudo 0 que fica encerrado se manifesta como "figura" contra 0 vasto fundo da paisagem. (NORBERGSCHULZ, 2006, p. 450).

Esse modo de pensar logocêntrico rompe com a continuidade da natureza e estabelece linhas e contornos, impondo um sistema de contigüidades: 0 assentamento, a arquitetura, contra a paisagem, mas também 0 tempo histórico contra o cíclico, as regras da gramática contra as formas iconográficas, a visibilidade dos conceitos contra a visualidade das imagens. Para McLuhan (1977, p. 339), não foi senão 0 alfabeto fonético que "envolveu os gregos num 'Espaço euclidiano' de ficção [...] ao trasladar o mundo audiotáctil para o mundo visual", criando "o sofisma do 'conteúdo', tanto na física como na literatura". Já Flusser (2007) associa o logocentrismo ao primado da linearidade da escrita na tradição ocidental cartesiana, contrapondo-se ao mundo imagético medieval e - 
agora - contemporâneo. De fato, a geometrização do espaço encontra no cartesianismo um sólido fundamento na própria constituição do cogito que contrapõe à interioridade do pensamento a exterioridade do mundo, marcada pela sua extensão e pela possibilidade de mensuração a partir de uma ordem racional que se pretende única. E é essa interioridade do pensamento que possibilita não só a cognição do mundo através de sua representação, comoque resulta, segundo Bauman (1999, p. 37-38), em uma concepção de espaço que se emoldura na relevância que os mapas adquirirem na construção de um espaço mensurável que o Estado-nação necessita para impor sua perspectiva e remover toda forma de dissonância interpretativa. É a partir desta constatação que Bauman (1999, p. 3738) argumenta que a "legibilidade do espaço" tornou-se um desafio do Estado moderno pela soberania de seus poderes. Isso incluía o controle do ofício de cartógrafo, já que 0 objetivo "da moderna guerra pelo espaço era a subordinação do espaço social a um e apenas um mapa oficialmente aprovado e apoiado pelo Estado" e ainda "imune ao processamento semântico por seus usuários ou vítimas".

\section{0 próximo e 0 distante como matrizes epistemológicas}

A mensurabilidade do espaço na modernidade define um modo de habitar enquanto controle das distâncias. É a relação entre o próximo e 0 distante 0 elemento epistemológico que define o jogo entre os enunciados e as visibilidades, o inteligível e o perceptível. Sustentando esta nossa hipótese, Bauman (1999, p. 34-36) lembra que antes que houvesse uma objetividade do espaço físico, a dimensão humana era a medida espacial. 0 corpo humano era efetivamente a condição de mensuração dos objetos nas mais diversas práticas sociais. Todavia, essa ordem subjetiva impedia um maior controle dos tributos e impostos por parte dos detentores do poder para com seus súditos, fazendo-se necessário "controlar e neutralizar o impacto da variedade e da contingência" através da "imposição de medidas padrão, obrigatórias, de distância, superfície, volume" e da proibição das "medidas locais, baseadas no grupo ou indivíduo". Antes, porém, de medir o espaço "objetivamente", era preciso ter claro uma idéia de "distância". Idéia que, na origem, está atrelada à distinção entre o "próximo" e 0 "longínquo" a partir da experiência pessoal e que será sistemática e progressivamente subvertida por uma ordem classificatória de demarcação da prática social. Das culturas "arcaicas" analisadas por LéviStrauss, chegando-se ao Estado moderno, teria havido sempre a necessidade do poder em submeter o espaço a sua autoridade direta, separando "as categorias e distinções espaciais das práticas humanas que os poderes do Estado não controlavam" e substituindo "as práticas locais e dispersas por práticas administrativas de Estado" como ponto de referência único. 
Há, assim, na relação entre o próximo e

0 distante, uma configuração espacial e

epistemológica que caracteriza uma forma

de habitar dependente de um diálogo entre a

interioridade e a exterioridade. Como lembra

Norberg-Schulz (2006, p. 448):

A propriedade básica dos lugares criados pelo homem é a concentração e o cercamento. Os lugares são literalmente "interiores", o que significa dizer que "reúnem" o que é conhecido. Para cumprir essa função, os lugares têm aberturas através das quais se ligam com 0 exterior.

A inspiração heideggeriana aqui é nítida: habitar significa estar em paz em um lugar protegido. 0 abrigo é um lugar habitável que nos faz pertencer ao entorno, que nos possibilita estar no mundo como condição da própria existência, como a marca expressiva de uma primeira pedra, de um primeiro assentamento, mas também como passagem de um caminho no qual nos instalamos e por onde 0 mundo passa.

Se toda linguagem sugere uma espacialização, uma certa disposição no espaço que, sem dominá-la, permite que dela nos aproximemos, então devemos compará-la a uma espécie de desbravamento, de abertura de um caminho. Um caminho que não tem de ser descoberto, mas inventado. E essa invenção de um caminho não é de modo algum alheia à arquitetura. Todo lugar na arquitetura, todo espaço habitado, tem uma precondição: que o edifício se localize em um caminho, em um cruzamento de ruas ou estradas pelos quais tanto se possa entrar como sair. Não há edifícios sem ruas que conduzam a ele ou que partam dele; tampouco existem edifícios sem percursos interiores, corredores, escadas, passagens, portas. Mas, se a linguagem não pode controlar o acesso a esses trajetos que levam ao edifício e que dele partem, isso apenas significa que a linguagem está implicada nessas estruturas, que ela está "a caminho", "movendo-se em direção à linguagem" dizia [Martin] Heidegger, a caminho de alcançar a si mesma. (DERRIDA, 2006, p. 167).

Devemos então entender o lugar não só como um abrigo, mas também como aquilo que nos permite entrar em contato com o mundo através de relações de vizinhança, de contigüidade, que lhe dão sentido. A construção de um lugar sendo a própria construção de um sentido que se tece entre as coisas, na medida em que as próprias coisas só vêm a ser por meio da linguagemjá que estas só vêm a ser por meio da linguagem que disponibiliza um modo de estar no mundo.

0 estabelecimento de um lugar habitável é um acontecimento e, evidentemente, esse estabelecimento sempre supõe algo de técnico. Inventa-se algo que não existia até então, mas, ao mesmo tempo, há o habitante, homem ou Deus, que requer esse lugar antes mesmo que ele tenha sido inventado ou produzido. Por isso, não se sabe muito bem onde situar a origem do lugar. Talvez habitemos um labirinto, que não é natural nem artificial, e que está no cerne da história da filosofia greco-ocidental, de onde se originou 0 antagonismo entre natureza e tecnologia. Dessa oposição nasce a distinção entre os dois labirintos. (DERRIDA, 2006, p. 168).

"Habitamos um lugar como habitamos no conceito. E essa territorialização que o conceito imprime ao pensamento atualiza-se na palavra, na linguagem, que ganha sentido na medida em que se constrói" (MASELLA LOPES, 2007, p. 140). E, por isso, podemos afirmar que a 
linguagem - e não apenas a arquitetura - atua mediante uma matriz espacial já que cumpre a função de dar um abrigo e situar o pensamento em meio ao caos cognitivo.

Posto que habitamos na linguagem, caberia então perguntarmo-nos: a comunicação pode ser entendida como habitabilidade? Como domínio de uma morada virtual? Se a escritura, como afirma Derrida, é como um labirinto, sem começo nem fim, a comunicação, enquanto linguagem, representaria alguma forma de abrigo? Se realmente habitamos na linguagem e esta se faz como um caminho, sua metáfora mais perversa não poderia ser outra que a da Torre de Babel. A pretensão em alcançar os céus, de ascender ao eixo transcendental fixando a linguagem em um lugar "acima" do mundo, em um supramundo, não poderia ser mais destoante da metáfora heideggeriana de buscar na casa a simultaneidade entre 0 acolhimento e a afirmação do mundo. Aqui, a arquitetura da Torre de Babel encontra o projeto da cidade cartesiana, da geometrização do espaço. 0 que era 0 controle do espaço como metáfora de um método (cartesiano) para controlar toda sorte de opiniões, e, assim, atingir à verdade, torna-se, aqui, metáfora de uma obra que visa garantir 0 controle da linguagem.

0 fato de que esta intervenção na arquitetura, com uma construção que também é uma desconstrução, represente o fracasso ou a limitação imposta sobre uma linguagem universal para impedir um plano de dominação política e lingüística do mundo nos informa sobre a im- possibilidade de controlar a multiplicidade das línguas, sobre a impossibilidade de existência de uma tradução universal. Significa também que a construção da arquitetura sempre permanecerá labiríntica. Não se trata de renunciar um ponto de vista em favor de outro, que seria único e absoluto, mas de encarar a diversidade de possíveis pontos de vista. (DERRIDA, 2006, p. 170).

Todavia, não é apenas na metáfora de Babel ou nos projetos utópicos de construção de cidades e repúblicas que encontramos uma estreita relação entre espaço, linguagem e poder. Vimos que a própria polis grega já trazia em sua gênese um projeto que não era só filosófico, mas político. Nesse sentido, a cidade não é apenas uma metáfora, mas o lugar privilegiado do controle das distâncias. Idéias, objetos e indivíduos encontram na cidade seus nós, seus pontos de acúmulo e tensão. Enfim, toda sorte de fluxos de bens materiais e imateriais condensam-se e ganham consistência na cidade, de modo que não se possa reduzir o fenômeno da compressão espaço-temporal ao ciberespaço sem antes admitir que a cidade tenha disponibilizado uma dimensão virtual antes dispersa na velocidade do pensamento.

\section{A virtualidade das cidades}

A virtualidade da cidade apresenta-se não só na eletricidade, que desde 0 início do século XX flui pelas linhas de energia que lhe atravessam por toda parte, mas também, e principalmente, pelo que a cidade se insinua com suas vitrines, seus anúncios, seus itinerários estriados nas 
linhas traçadas pelas ruas, e com sua arquitetura, que acumula nas fachadas o tempo em diversas escrituras. A cidade não é mais esse abrigo interior e artificial da natureza que, como extensão da casa, protege-nos do caos de um mundo exterior, já que, há muito tempo, esse limite se diluiu. Ao contrário, a virtualidade da cidade está em sua polissemia, em seus devires; nos sentidos que se abrem à multiplicidade de fluxos que se processam em seu meio. Meio ambiente que é meio técnico. A cidade deixa de exprimir a materialidade dos objetos para emergir enquanto sistema de signos com todas as implicações políticas que isso acarreta, assim como a linguagem não pode mais se reduzir à escrita para assumir um contexto mais amplo que inclua os códigos visuais.

Aprendendo com Las Vegas, de Venturi e Brown (2006), ilustra essa transformação do espaço urbano em uma espécie de simulacro do mundo mercadológico e publicitário, ao discutir em que medida a arquitetura, apropriada pelo modo de produção capitalista, teria descaracterizado uma certa "aura do espaço" que sempre prescindiu de um ideal estético como índice de autenticidade e valor do espaço construído. Os autores referem-se ao advento do corredor comercial, especialmente a Las Vegas Strip - seu exemplo por excelência -, em que a arquitetura das fachadas assume 0 caráter pictórico das superfícies luminosas em detrimento da tradicional concepção de espaço tridimensional própria dos interiores. Ao "cinismo" dessa apropriação mercadológica do espaço urbano, Kenneth Frampton (2006, p. 477-478) contraargumenta da seguinte forma:

Absolvemos a Strip, por medo de admitir que talvez tenhamos eliminado para sempre toda possibilidade de estar em algum lugar. Nós nos gabamos de nossa tão valorizada mobilidade, de nossa rush city ["cidade da pressa"] [...] só para descobrir que, se parássemos, haveria poucos lugares nos quais qualquer um de nós escolheria estar. Trocamos, com alegre inconseqüência, nossa já débil influência na esfera pública pelo aturdimento eletrônico da esfera privada do futuro.

Evidentemente, o que aqui se discute é a

legitimidade da arquitetura como linguagem impondo-se à arquitetura como espaço em uma sociedade imagética - de ubiqüidade da comunicação visual:

0 trevo rodoviário e 0 aeroporto se comunicam com multidões em movimento, de carro ou a pé, por razões de eficiência e segurança. Mas as palavras e os símbolos também podem ser usados no espaço para a persuasão comercial. Se nas feiras do Oriente Médio não há placas ou letreiros, a Strip é praticamente toda sinais. Nas feiras, a comunicação se faz pela proximidade. Caminhando por suas estreitas aléias, os compradores sentem e cheiram as mercadorias, $\mathrm{e}$ 0 comerciante se encarrega da persuasão explícita. Nas ruas estreitas da cidade medieval, embora houvesse sinais, a persuasão se fazia principalmente pela visão e pelo cheiro de bolos e pães concretos, através das portas e janelas da padaria. (VENTURI; BROWN, 2006, p. 344).

Ora, essa questão de contrapor a cidade como linguagem à cidade como lugar, remetenos também à produção dos não-lugares de Marc Augé (1994, p. 73) que, na chamada 
"supermodernidade", apresentam-se como espaços que "não são em si antropológicos", contrapondo-se "aos lugares antigos: estes, repertoriados, classificados e promovidos a 'lugares de memória"'. Significa dizer que os não-lugares, por desconhecerem a identidade, a singularidade e a permanência do "lugar antropológico", assumem a repetibilidade e a transitoriedade das imagens seriais da contemporaneidade. Essa proliferação de imagens da supermodernidade forma então um mundo de consumo, um sistema autopoiético - rádios fazem propaganda de lojas que fazem propaganda da rádio - em que a busca pelo anonimato torna-se uma bizarra forma de compartilhar uma identidade.

Todavia, cremos que não seria o caso de opormos o lugar ao não-lugar, imputando a este uma negatividade, pois não se trata de impugnar o espaço repertoriado do lugar ao não-repertoriado do não-lugar, já que 0 repertório depende do modo como lemos os espaços pelos quais caminhamos. Crer de forma incondicional nessa dicotomia seria negar a produção de subjetividade a qual refaz os caminhos daquilo que é visível. Como lembram Deleuze e Guattari (1997, p. 184-190), tanto o espaço liso dos mares e do campo pode ser estriado pela navegação e agricultura, como 0 espaço estriado das cidades pode tornar-se liso quando não sujeito às forças de estriagem do capitalismo. Tudo depende do modo pelo qual circulam esses espaços.
Ora, a questão que Venturi e Brown (2006, p. 344-346) nos colocam caminha em uma direção paralela àquela abordada por Augé. Trata-se do domínio de uma semiótica da cidade sobre 0 "puro espaço da arquitetura". 0 letreiro torna-se mais importante que a arquitetura, a comunicação torna-se mais importante que 0 espaço. "A contradição entre 0 exterior e 0 interior" desfaz-se com uma arquitetura de falsas fachadas em escalas apropriadas aos usuários agora invariavelmente motorizados. "Se tirarmos os letreiros, não existe o lugar". É claro que sempre podemos argumentar que uma cidade - qualquer uma, mesmo as mais antigas - pode ser lida de uma forma semiótica. A diferença, contudo, é que agora a arquitetura não é mais um modo de expressar a forma ou a função de um ambiente - ou o sublime, como afirma Derrida -, mas é um mero suporte de sinais, símbolos e peças publicitárias. A cidade já não tem mais um caráter ou identidade senão aquele que os meios de comunicação ocupam por toda paisagem. Os edifícios tornam-se suportes de peças publicitárias e os outdoors proliferam pelas avenidas, reproduzindo uma seqüência de instantâneos como em um filme, obliterando a paisagem de um fundo natural. Cria-se assim uma arquitetura de superfícies, uma arquitetura sem profundidade, em que a experiência do espaço ocorre como no dispositivo do mecanismo cinematográfico: como uma sucessão de quadros postos em movimento, só que agora pela velocidade do carro. 


\section{Uma arquitetura de superfícies}

A arquitetura então se equipara a um jogo de interfaces tal como Paul Virilio (1993) refere-se acerca dos meios imagéticos da comunicação. A superfície aqui evocada é a da aniquilação do espaço e, por conseqüência, do próprio tempo como cronologia. A interface da tela seria a superfície onde "o esgotamento do relevo natural e das distâncias de tempo achata toda localização e posição" e em que "a instantaneidade da ubiqüidade" resulta em uma "atopia". Isso nos coloca diante de uma nova representação, diante de uma nova ordem cognitiva, em que a luz não é mais a metáfora de um mundo inteligível, mas em que a essência e a aparência diluem-se, ou concentram-se, na própria luz como dimensão de uma nova realidade. Se a medida, através de seus diversos instrumentos, contribuiu "para a constante redefinição do espaço percebido, do espaço vivido e, portanto, indiretamente, para a determinação cada vez mais rigorosa da imagem do mundo sensível", hoje, presenciamos uma transferência dessa "matéria mensurada e agrimensada para a luz mensuradora", inaugurando "efetivamente uma mutação na avaliação científica do tempo e do espaço".

Ocorre que se a luz tem sua grandeza não mais medida por sua espacialidade - como 0 são as figuras -, mas por sua velocidade, seu movimento - sem repouso -, torna-se então não mais um atributo de sua matéria, mas sua própria condição. A forma-imagem luz apresenta- se ao pensamento não mais como passível de representação, mas como própria "representação de si mesma", como presença absoluta que desfaz 0 esforço técnico de intervir sobre a natureza através de instrumentos de medição, pois ela própria é medição. Assim, todo o esforço da ciência moderna em afastar a metafísica dos fenômenos naturais através do aprimoramento de instrumentos técnicos de medição dos objetos que resultariam em leis universais de causalidade - do movimento dos corpos -, parece desabar quando a velocidade da luz em sua formaimagem sempre atual cria uma superfície nova, ocultando de nossas representações o fundo natural. Através dessa nova imagem sintética, desfaz-se o mundo físico dos objetos extensos e mergulhamos em um mundo da representação eletrônica em que a luz não mais dá forma aos objetos, mas transfigura-se no próprio objeto. Evidentemente, a luz que protagoniza a forma-imagem que se apresenta nos suportes eletrônicos pelas tecnologias da comunicação não é a mesma que aquela dos letreiros luminosos que proliferam nas cidades, mas podemos aproximar essa ubiqüidade da imagem e a sua conseqüente eliminação das distâncias com uma leitura da transformação do espaço urbano em suporte de uma comunicação visual.

Como afirma Virilio (1993, p. 22-23):

A partir de agora assistimos (ao vivo ou não) a uma co-produção da realidade sensível na qual as percepções diretas e mediatizadas se confundem para construir uma representação ins- 
tantânea do espaço, do meio ambiente. Termina a separação entre a realidade das distâncias (de tempo, de espaço) e a distanciação das diversas representações (videográficas, iconográficas). A observação direta dos fenômenos visíveis é substituída por uma teleobservação na qual 0 observador não tem mais contato imediato com a realidade observada.

Ainda segundo Virilio (1993, p.23), isso implica não só em uma alteração considerável de nossa percepção da realidade, como "engendra um perigoso desequilíbrio entre o sensível e 0 inteligível", já que não temos mais como discernir a realidade midiática de um fundo natural que sempre se constituiu enquanto verdadeiro. 0 que emerge e se sobrepõe desse fundo natural é a imagem sintética que surge nas interfaces dos aparelhos tecnológicos de comunicação. As telas de televisão, os monitores dos computadores, os visores dos celulares: são através dessas zonas de interface que nos deparamos com a supremacia da imagem na era da comunicação. É com a imagem que cada vez mais interagimos no nosso cotidiano, essa imagem sem profundidade, sem textura, sem gosto ou odor, ocupa agora o lugar do assentamento e da figura contra todo fundo natural que se torna então desinteressante: violento, perigoso, estressante.

Assim como o corpo, os mapas e as cidades definem um modo de operar as distâncias,; os meios técnicos de comunicação também agora o fazem. Mas, é controversa a idéia de que eles eliminem as distâncias. Sobre esse aspecto, Karsten Harries (2006, p. 425) diz:
As conseqüências definitivas dessa investida contra as distâncias ainda são incertas: embora prometam ao homem um poder quase divino, também 0 ameaçam com uma situação de desamparo que ele jamais conheceu. Existem, sem dúvida, os que esperam uma nova situação de intimidade a partir da revolução dos meios de transporte e da comunicação: 0 homem passará a sentir-se como em sua casa no mundo e junto dos outros como jamais pôde sentir-se antes. Mas a metáfora de Marshall McLuhan sobre a "aldeia global" é enganosa. [...] A eliminação das distâncias e os artifícios de distanciamento só podem voltar-se contra a intimidade, pois a intimidade requer distância; abolir uma é abolir ao mesmo tempo a outra. Em vez de uma genuína proximidade, o que nos oferecem é um análogo perverso: a eqüidistância e, portanto, a homogeneidade e a indiferença do lugar. Quando todos os lugares têm o mesmo valor, não nos podemos situar e nos tornamos deslocados.

A velocidade disponibilizando as imagens instantaneamente através da superfície luminosa da interface cria um campo de eventos que se equiparam em valor de grandeza. Tudo se torna "compactável" na dimensão da tela do visor, tornando o passado presente e 0 distante próximo. Os eventos apresentam-se como uma colagem disposta em um fluxo de imagens em que a história e a geografia são negadas, anulando qualquer sensação de volume ou profundidade.

Como afirma Virilio (1993, p. 24),

Diante desta súbita facilidade de passar sem transição ou espera da percepção do infinitamente pequeno para a percepção do infinitamente grande, da imediata proximidade do visível para a visibilidade do que está para além do campo visual, a antiga distinção entre as dimensões desaparece. (grifo do autor) 
Uma percepção não mais restrita às dimensões, mas da representação instantânea de dados.

Diante desse "desequilíbrio entre a informação direta de nossos sentidos e a informação mediatizada das tecnologias avançadas" em que "nossos julgamentos de valor, nossa medida das coisas" é transferida "do objeto para sua figura, da forma para sua imagem", o risco que corremos é, conforme alerta Virilio (1993, p. 40), de "um delírio generalizado de interpretação".

As tecnologias da comunicação processam uma ruptura epistemológica em que a imagem ocupa o lugar da natureza não enquanto representação, mas como o próprio real. Não se trata aqui de considerar os conteúdos que operam através dessas imagens, mas de perceber que a técnica não é mais um instrumento de intelecção da realidade, mas torna-se o padrão de medida através do qual toda realidade é posta à prova. Significa dizer que a técnica descola-se da ciência, ganha autonomia diante dos fenômenos físicos observáveis na medida em que atua como prova científica. Se a ciência surge como forma de conhecer a verdade dos fenômenos físicos e a comprovação dos mesmos depende da eficiência dos instrumentos técnicos para medir suas formas e os movimentos, e se essa mesma ciência constata que a verdade dos fenômenos é refém de suas técnicas de manipulação, então a técnica torna-se 0 novo mito de uma era em que a velocidade aproxima a física e a metafísica. 0corre que a eliminação das distâncias não é apenas um fenômeno das tecnologias da comunicação que possibilitam uma desconstrução da materialidade do espaço geográfico, mas também da ubiqüidade da imagem em todos os espaços físicos da cidade, transformando-a em um enorme hipertexto e eliminando todos os volumes das formas arquitetônicas. A cidade passa a não ser mais percebida pelo corpo, mas pelo olhar. 0 efeito da apreciação dos signos de uma cidade vista sempre a partir de "um dentro" de um veículo em movimento, achata seu relevo e textura tal qual observamos nas interfaces dos suportes eletrônicos, provocando, segundo Virilio (1993, p. 19), uma "crise da noção de dimensão" ou "a crise do inteiro", ou seja, a crise

[...] de um espaço substancial, homogêneo, herdado da geometria grega arcaica, em benefício de um espaço acidental, heterogêneo, em que as partes, as frações, novamente tornam-se essenciais, atomização, desintegração das figuras, dos referenciais visíveis que favorecem todas as transmigrações, todas as transfigurações.

Mas também a crise de um sujeito vencido pela técnica, que assiste "desde o início do século XX", "a profundidade de campo das perspectivas clássicas" ser renovada "pela profundidade de tempo das técnicas avançadas". Essa "crise da noção de dimensão e do inteiro" também é enunciada por Harvey (2004), que a converte em sintoma de um discurso tecno-científico que encontraria suas razões em uma nova 
ordem sócio-econômica que se impõe como hegemônica a partir do crescimento das forças capitalistas de produção. Entretanto, a sujeição dessa crise da dimensão a uma ordem políticoeconômica permanece aquém do entendimento dos processos de operacionalização que levam ao desabrigo do ser diante dessa nova condição espaciotemporal. Para tanto, será preciso antes entender de que maneira essas imagens midiáticas preenchem 0 imaginário social, encontrando uma correspondência no sistema sócio-psíquico equivalente àquela que 0 fetiche desempenha nas relações com as mercadorias.

\section{0 habitar: entre a natureza e a técnica}

Se a relação entre o próximo e 0 distante estrutura-se como condição do "estar no mundo", é muito porque se entende "este mundo" por "mundo natural" que, para vivenciá-lo, é preciso percorrê-lo observando as determinações de uma espacialidade mensurável. No entanto, 0 valor do espaço não pode ser medido pela sua materialidade, pela sua possibilidade de mensuração, mas pela sua territorialidade, pela fluidez dos limites que contrai ao se diferenciar dos demais espaços. A inclusão ou exclusão social, não estando mais necessariamente circunscrita aos limites materiais da cidade, mas aos espaços imateriais das subjetividades, passa a se tornar objeto do discurso midiático ao exercer o controle do que deve ou não se tornar visível, fazendo da relação espacial interior-exterior um dispositivo ainda extremamente eficaz de controle social.
0 legítimo passa então a habitar o que está dentro do espaço visível das mídias, enquanto as subjetividades ou práticas dissonantes mantêm-se fora desse olhar midiático, tornando-se unicamente visíveis enquanto algo antagônico ou ameaçador à ordem estabelecida, enquanto negatividade.

0 espaço não está nas coisas, mas na relação que estabelecemos com as coisas. 0s mapas geográficos não definem uma espacialidade senão aquela que imputamos através de uma ordem, seja esta política, etnográfica ou topográfica. Da mesma forma, a comunicação não pode ser circunscrita a um único mapa, porque não está sujeita a uma única gramática que lhe designe 0 que é. Já que há várias ordens, falemos, portanto, em vários mapas, ou ainda, em várias linguagens.

Habitamos e somos habitados por diversas linguagens que nos fornecem a visibilidade do real a partir de sua organização em códigos verbais e visuais. Este é o pressuposto que nos possibilita entender a cidade como uma forma possível de habitar comprimida entre uma narrativa mítica acerca da natureza e outra tecnológica, que adquire uma dimensão virtual com os meios técnicos de comunicação. Assumindo o lugar do logos, a cidade é, ao mesmo tempo, resultado de uma construção da política e do fortalecimento da palavra escrita como forma de publicidade. Conseqüentemente, o que fundamentalmente habitamos não é apenas a cidade em sua concretude, mas um sistema de 
signos verbais e visuais, ou seja, é a linguagem que nos permite a visibilidade, ou a forma $\mathrm{e}$ o conteúdo do real, assim como possibilita situarmo-nos na espaciotemporalidade própria a cada estrato ou formação histórica. Estrato que, na contemporaneidade, tem sido marcado pela criação de um ambiente cognitivo cuja condição atual é de proximidade, continuidade e visibilidade tecnicamente mediada, alterando nossa matriz espaciotemporal e, portanto, nosso imaginário urbano cujas conseqüências no espaço público ainda são incertas.

\section{Referências bibliográficas}

AUGÉ, Marc. Não-lugares: introdução a uma antropologia da supermodernidade. Campinas: Papirus, 1994.

BAUMAN, Zygmunt. Globalização: as consequiências humanas. Rio de Janeiro: Zahar, 1999.

DELEUZE, Gilles; GUATTARI, Félix. Mil platôs: capitalismo e esquizofrenia, v. 5. São Paulo: 34, 1997. DERRIDA, Jacques. Uma arquitetura onde o desejo possa morar: entrevista de Jacques Derrida a Eva Meyer. In: NESBITT, Kate (org.). Uma nova agenda para a arquitetura: antologia teórica (1965-1995). São Paulo: Cosac Naify, 2006.

FLUSSER, Vilém. 0 mundo codificado. São Paulo: Cosac Naif, 2007.

FRAMPTON, Kenneth. Uma leitura de Heidegger. In: NESBITT, Kate (org.). Uma nova agenda para a arquitetura: antologia teórica (1965-1995). São Paulo: Cosac Naify, 2006.

HARRIES, Karsten. A função ética da arquitetura. In: NESBITT, Kate (org.). Uma nova agenda para a arquitetura: antologia teórica (1965-1995). São Paulo: Cosac Naify, 2006.
HARVEY, David. A condição pós-moderna. 13. ed. São Paulo: Loyola, 2004.

HEIDEGGER, Martin. Ensaios e Conferências. Petrópolis: Vozes, 2002.

\section{MASELLA LOPES, Paulo Roberto. 0 espaço como} matriz epistemológica na comunicação. 2007. Dissertação (Mestrado em Ciências da Comunicação Epistemologia, Teoria e Metodologia da Comunicação ÁREA) - Escola de Comunicação e Artes, Universidade de São Paulo, 2007.

MCLUHAN, Marshall. A galáxia de Gutenberg: a formação do homem tipográfico. 2. ed. São Paulo: Companhia Editora Nacional, 1977.

MERLEAU-PONTY, Maurice. Fenomenologia da Percepção. $2^{a}$ edição. São Paulo: Martins Fontes, 1999.

NORBERG-SCHULZ, Christian. 0 fenômeno do lugar. In: NESBITT, Kate (org.). Uma nova agenda para a arquitetura: antologia teórica (1965-1995). São Paulo: Cosac Naify, 2006. 0 pensamento de Heidegger sobre arquitetura. In: NESBITT, Kate (org.). Uma nova agenda para a arquitetura: antologia teórica (19651995). São Paulo: Cosac Naify, 2006.

VENTURI, Robert; SCOTT BROWN, Denise. Uma significação para os estacionamentos dos supermercados A\&P, ou Aprendendo aprendendo com Las Vegas. In NESBITT, Kate (org.). Uma nova agenda para a arquitetura: antologia teórica (1965-1995). São Paulo: Cosac Naify, 2006.

VERNANT, Jean-Pierre. As origens do pensamento grego. 4. ed. São Paulo: DIFEL, 1984.

VIRILIO, Paul. 0 espaço crítico - e as perspectivas do tempo real. Rio de Janeiro: 34, 1993. 


\section{Language as a way of inhabiting: the close and the distant}

\section{Abstract}

This essay intends to argue about communication and city from notions of proximity and distance. Usually, it is granted to new technologies of communication the primacy for dominating the virtual space, as well as to the architecture dominates the construction of concrete spaces of materiality. Without any doubt, the technical ways of communication bring out a crisis into space matrix since they reorganize the perception of distance; however, we believe that production of subjectivity cannot be apart from a thought virtualizing process that recreates the meaning of the space itself. As a result, we have to consider that forms of inhabiting may not be reduced to the measurement of the concrete space, but depends on languages that produce the visibility of real.

\section{Keywords}

Space. Language. Inhabiting.

\section{El lenguaje como forma de habitar: lo lejano y lo cercano}

\section{Resumen}

Esta ponencia tiene el objetivo de discutir la relación entre la comunicación y la ciudad desde las nociones de proximidad y distancia. Usualmente, se concede a las nuevas tecnologías de la comunicación la primacía por el dominio del espacio virtual, así como a la arquitectura en la construcción de los espacios concretos de la materialidad. Sin duda, los medios técnicos de la comunicación, al reorganizar la percepción de las distancias, suscitan una crisis de matriz espacial; sin embargo, creemos que no se pueda excluir la producción de subjetividad como un proceso de virtualización del pensamiento que rehace el propio sentido del espacio. Como resultado, tenemos que las formas de habitar no se reducen a la mensuración del espacio concreto, pero dependen de los lenguajes que producen la visibilidad del real.

\section{Palabras clave}

Espacio. Lenguaje. Habitar. 


\section{Expediente}

A revista E-Compós é a publicação científica em formato eletrônico da Associação Nacional dos Programas de Pós-Graduação em Comunicação (Compós). Lançada em 2004, tem como principal finalidade difundir a produção acadêmica de pesquisadores da área de Comunicação, inseridos em instituições do Brasil e do exterior.
E-COMPÓS I www.e-compos.org.br I E-ISSN 1808-2599

Revista da Associação Nacional dos Programas de Pós-Graduação em Comunicação. Brasília, v.11, n.2, maio/ago. 2008

A identificação das edições, a partir de 2008 passa a ser volume anual com três números.

\section{CONSELHO EDITORIAL}

\section{Afonso Albuquerque}

Universidade Federal Fluminense, Brasil

Alberto Carlos Augusto Klein

Universidade Estadual de Londrina, Brasi

Alex Fernando Teixeira Primo

Universidade Federal do Rio Grande do Sul, Brasi

Alfredo Vizeu

Universidade Federal de Pernambuco, Brasil

Ana Carolina Damboriarena Escosteguy

Pontifícia Universidade Católica do Rio Grande do Sul, Brasil

Ana Silvia Lopes Davi Médola

Universidade Estadual Paulista, Brasil

André Luiz Martins Lemos

Universidade Federal da Bahia, Brasil

Ângela Freire Prysthon

Universidade Federal de Pernambuco, Brasil

Antônio Fausto Neto

Universidade do Vale do Rio dos Sinos, Brasil

Antonio Carlos Hohlfeldt

Pontifícia Universidade Católica do Rio Grande do Sul, Brasil

Arlindo Ribeiro Machado

Universidade de São Paulo, Brasil

César Geraldo Guimarães

Universidade Federal de Minas Gerais, Brasi

Cristiane Freitas Gutfreind

Pontifícia Universidade Católica do Rio Grande do Sul, Brasil

Denilson Lopes

Universidade Federal do Rio de Janeiro, Brasil

Eduardo Peñuela Cañizal

Universidade Paulista, Brasil

Erick Felinto de Oliveira

Universidade do Estado do Rio de Janeiro, Brasil

Francisco Menezes Martins

Universidade Tuiuti do Paraná, Brasil

Gelson Santana

Universidade Anhembi/Morumbi, Brasil

Hector Ospina

Universidad de Manizales, Colômbia

leda Tucherman

Universidade Federal do Rio de Janeiro, Brasil

Itania Maria Mota Gomes

Universidade Federal da Bahia, Brasil

Janice Caiafa

Universidade Federal do Rio de Janeiro, Brasil

Jeder Silveira Janotti Junior

Universidade Federal da Bahia, Brasil
John DH Downing

University of Texas at Austin, Estados Unidos

José Luiz Aidar Prado

Pontifícia Universidade Católica de São Paulo, Brasil

José Luiz Warren Jardim Gomes Braga

Universidade do Vale do Rio dos Sinos, Brasi

Juremir Machado da Silva

Pontifícia Universidade Católica do Rio Grande do Sul, Brasil

Lorraine Leu

University of Bristol, Grã-Bretanha

Luiz Claudio Martino

Universidade de Brasília, Brasil

Maria Immacolata Vassallo de Lopes

Universidade de São Paulo, Brasil

Maria Lucia Santaella

Pontifícia Universidade Católica de São Paulo, Brasil

Mauro Pereira Porto

Tulane University, Estados Unidos

Muniz Sodre de Araujo Cabral

Universidade Federal do Rio de Janeiro, Brasil

Nilda Aparecida Jacks

Universidade Federal do Rio Grande do Sul, Brasil

Paulo Roberto Gibaldi Vaz

Universidade Federal do Rio de Janeiro, Brasil

Renato Cordeiro Gomes

Pontifícia Universidade Católica do Rio de Janeiro, Brasil

Ronaldo George Helal

Universidade do Estado do Rio de Janeiro, Brasil

Rosana de Lima Soares

Universidade de São Paulo, Brasil

Rossana Reguillo

Instituto Tecnológico y de Estudios Superiores do Occidente, México

Rousiley Celi Moreira Maia

Universidade Federal de Minas Gerais, Brasil

Sebastião Carlos de Morais Squirra

Universidade Metodista de São Paulo, Brasil

Simone Maria Andrade Pereira de Sá

Universidade Federal Fluminense, Brasil

Suzete Venturelli

Universidade de Brasília, Brasil

Valério Cruz Brittos

Universidade do Vale do Rio dos Sinos, Brasil

Veneza Mayora Ronsini

Universidade Federal de Santa Maria, Brasil

Vera Regina Veiga França

Universidade Federal de Minas Gerais, Brasil

\section{COMISSÃO EDITORIAL}

Ana Gruszynski I Universidade Federal do Rio Grande do Sul, Brasil João Freire Filho I Universidade Federal do Rio de Janeiro, Brasil Rose Melo Rocha I Escola Superior de Propaganda e Marketing, Brasil

\section{CONSULTORES AD HOC}

Aníbal Bragança I Universidade Federal Fluminense, Brasi Gisela Castro I Escola Superior de Propaganda e Marketing, Brasil

Gislene Silva I Universidade Federal de Santa Catarina, Brasil

Maria Helena Weber I Universidade Federal do Rio Grande do Sul, Brasil

Rosana de Lima Soares I Universidade de São Paulo, Brasil

Tania Hoff I Escola Superior de Propaganda e Marketing, Brasil

REVISÃO DE TEXTO E TRADUÇÃo I Everton Cardoso

ASSISTÊNCIA EDITORIAL E EDITORAÇÃO ELETRÔNICA I Raquel Castedo
COMPÓS I www.compos.org.br

Associação Nacional dos Programas de Pós-Graduação em Comunicação

Presidente

Erick Felinto de Oliveira

Universidade do Estado do Rio de Janeiro, Brasil erickfelinto@uol.com.br

Vice-presidente

Ana Silvia Lopes Davi Médola

Universidade Estadual Paulista, Brasil

asilvia@faac.unesp.br

Secretária-Geral

Denize Correa Araújo

Universidade Tuiuti do Paraná, Brasil

denizearaujo@hotmail.com 